\title{
DNA-repair genetic polymorphisms and risk of breast cancer in Cyprus
}

\author{
Maria A. Loizidou - Thalia Michael · Susan L. Neuhausen · Robert F. Newbold · \\ Yiola Marcou · Eleni Kakouri · Maria Daniel · Panayiotis Papadopoulos · \\ Simos Malas · Andreas Hadjisavvas · Kyriacos Kyriacou
}

Received: 26 May 2008/ Accepted: 27 May 2008/Published online: 16 June 2008

(C) Springer Science+Business Media, LLC. 2008

\begin{abstract}
The DNA repair pathway is known to play a role in the etiology of breast cancer. A number of studies have demonstrated that common germline variants in genes involved in the DNA repair pathway influence breast cancer risk. To assess whether alterations in DNA repair genes contribute to breast cancer, we genotyped 12 single nucleotide polymorphisms (SNPs) in 1,109 Cypriot women with breast cancer and 1,177 age-matched healthy controls. We found significant associations with breast cancer for SNPs in the BRCA2 and MRE11A genes. Carriers of the $B R C A 2$ rs 1799944 variant (991 Asp) were found to have an increased risk of breast cancer $(\mathrm{OR}=1.41,95 \%$ CI 1.08 $1.83, P=0.01)$ with $P_{\text {trend }}=0.0076$. Homozygous carriers of the MRE11A rs601341 A allele had an increased risk of breast cancer $(\mathrm{OR}=1.36,95 \%$ CI $1.08-1.71$,
\end{abstract}

M. A. Loizidou · T. Michael · A. Hadjisavvas ( $₫)$.

K. Kyriacou

Department of Electron Microscope/Molecular Pathology,

The Cyprus Institute of Neurology and Genetics,

6, International Airport Ave., Ayios Dometios,

P.O. Box 23462, 1683 Nicosia, Cyprus

e-mail: ahsavvas@cing.ac.cy

\section{S. L. Neuhausen}

Department of Epidemiology, School of Medicine, University of California Irvine, Irvine, CA 92697-7550, USA

R. F. Newbold

Brunel Institute of Cancer Genetics and Pharmacogenomics, Faculty of Life Sciences, Brunel University, Uxbridge,

United Kingdom

Y. Marcou · E. Kakouri · M. Daniel · P. Papadopoulos

Bank of Cyprus Oncology Center, Nicosia, Cyprus

S. Malas

Department of Oncology, Limassol General Hospital,

Limassol, Cyprus
$P=0.009)$ with $P_{\text {trend }}=0.0087$. This study suggests that genetic variants in BRCA2 and MRE1IA are associated with breast cancer risk.

Keywords Breast cancer - Case-control study · Cyprus - DNA repair genes - Genetic epidemiology · SNP

\section{Introduction}

Breast cancer is the most common malignancy affecting women worldwide and it is the leading female cancer in Cyprus, with approximately 350-400 new cases diagnosed annually [1].

The DNA repair pathway is essential for maintaining genomic stability of mammalian cells. Deficiencies in DNA repair mechanisms lead to high penetrance genetic syndromes such as Fanconi anemia and Bloom syndrome, which have cancer as a predominant phenotype [2]. Ten different genes, involved in pathways critical to genomic integrity, have been implicated in inherited predisposition to breast cancer. Germline mutations in these genes significantly increase breast cancer risk and thus support a major role of the DNA repair pathway in breast carcinogenesis. The most important of these genes are BRCAl and $B R C A 2$ [3]. There is also evidence from in vitro studies that reduced DNA repair capacity is associated with increased breast cancer risk $[4,5]$.

The known breast cancer susceptibility genes have been estimated to explain only $5 \%$ of breast cancer cases, thus it is likely that other breast cancer susceptibility genes exist [6]. Based on the fact that the DNA repair pathway is involved in familial breast cancer it was suggested that single nucleotide polymorphisms (SNPs) in genes involved 
in DNA repair may influence DNA repair capacity and, in turn, confer an altered susceptibility to develop breast cancer. Several studies have investigated the role of SNPs in DNA repair genes in relation to breast cancer and have reported associations with breast cancer risk [7-10].

In this study, we hypothesized that genetic variation in the DNA repair pathway may modify susceptibility to breast cancer in Cypriot women. As part of an ongoing study we assessed genetic variation in 12 SNPs in 11 DNA repair-related pathway genes, specifically $B A R D 1, B R C A 2$, ERCC2, FANCA, MLH1, MRE11A, MSH2, OGG1, RAD51, $R A D 52$, and TP53 and their association with breast cancer in a case-control study of Cypriot women.

\section{Materials and methods}

\section{Subjects}

The study population was women participating in the MASTOS study, a population-based case-control study of breast cancer in Cyprus [11]. Blood samples were collected between 2004 and 2006 from 1,109 female breast cancer patients diagnosed between 40 and 70 years old and 1,177 aged-matched healthy controls. Cases participating in the study were women previously diagnosed with breast cancer between January 1999 and December 2006. In addition to blood samples, a risk factor questionnaire that included extensive demographic, epidemiological, and pathological data was obtained from each participant through a standardized interview. Breast cancer cases were verified by reviewing histological reports. The study was approved by the National Bioethics Committee of Cyprus, and all participants provided signed informed consent.

\section{Genotyping}

DNA was isolated from blood samples using standard procedures (phenol-chloroform method). The 12 single nucleotide polymorphisms (SNPs): BARD1 rs1048108 (Pro24Ser), BRCA2 rs1799944 (Asn991Asp), ERCC2 rs13181 (Lys751Gln), FANCA rs2239359 (Gly501Ser), MLH1 rs1799977 (Ile219Val), MRE11A rs601341, MSH2 rs2059520, OGG1 rs1052134 (Ser326Cys), RAD51 rs 1801320 and rs1801321 (135G $>$ C-5'UTR and 172 $\left.\mathrm{G}>\mathrm{T}-5^{\prime} \mathrm{UTR}\right)$, RAD52 rs11226 (2259 C > T-3'UTR) and TP53 rs1042522 (Pro72Arg) were genotyped in all subjects participating in the study. All SNPs studied had a minor allele frequency of over 0.05. Genotyping was performed using the Taqman SNP genotyping assays from Applied Biosystems Inc. (ABI). For genotyping SNP rs1801320 the primers and probes described previously by Kuschel et al. were used [8]. Each assay was carried out using $10 \mathrm{ng}$ genomic DNA in a $5 \mu$ reaction using Taqman Universal PCR Master Mix (ABI), forward and reverse primers, and FAM and VIC-labelled probes purchased from Applied Biosystems (ABI Pre-Designed assays). All assays were carried out in 384-well plates. The fluorescence profile was read on an ABI PRISM 7900HT instrument and the results analyzed with Sequence Detection Software (ABI). For quality control, random samples were genotyped in duplicate and had identical genotyping assignments. Genotype call rates ranged from $99 \%$ to $100 \%$ and duplicate concordance rates were higher than $99 \%$.

\section{Data analysis}

We performed a chi square test $\left(\chi^{2}\right)$ to assess Hardy-Weinberg equilibrium (HWE) in the control samples. Genotype frequencies were compared across groups using the $\chi^{2}$ test and the Mantel-Haenzel test for linear trend. The association between breast cancer and each SNP was examined using logistic regression with the SNP genotype tested under models of complete dominance and recessive inheritance. Statistical analysis was carried out using the SPSS v 13 software (SPSS Inc., Chicago, Illinois) and GraphPad InStat v 3.06 (GraphPad Software, San Diego California).

\section{Results}

Genotype distributions of controls at each locus were consistent with HWE. However, the RAD51 genotype frequencies in the controls were not in HWE $(P<0.05)$, but were similar to the frequencies reported by the HapMap Project (www.hapmap.org) [12]. This may be due to hidden population structures that specifically affect RAD51. Neither of the RAD51 SNPs were associated with breast cancer. Table 1 summarizes the distribution of genotypes among cases and controls, as well as the allele frequencies of the 12 SNPs under study.

The median ages of both the breast cancer cases and the controls were 56 years. The mean age at diagnosis for the breast cancer cases was 51.6 years (standard deviation (SD) \pm 9.2 ) and mean age at ascertainment for the controls was 56.4 years $((\mathrm{SD}) \pm 9.2)$.

The associations of the SNPs and breast cancer risk in Cypriot women are shown in Table 2. We found significant associations of the BRCA2 rs1799944 (Asn991Asp) and $M R E 11 A$ rs601341 variants and breast cancer risk. Carriers of BRCA2 991 Asp were found to have an increased risk of breast cancer $(\mathrm{OR}=1.41,95 \%$ CI $1.08-1.83, P=0.01)$ with $P_{\text {trend }}=0.0076$. Homozygous carriers of the MRE11A rs601341 A allele had an increased risk of breast cancer $(\mathrm{OR}=1.36,95 \% \mathrm{CI} 1.08-1.71, P=0.009)$ with $P_{\text {trend }}=0.0087$. A marginal association $(P=0.05)$ was 
Table 1 Genotypes and allele frequencies for the 12 SNPs under study

\begin{tabular}{|c|c|c|c|c|c|c|c|}
\hline Gene/SNP & Cases & Controls & $P$-value ${ }^{\mathrm{a}}$ & Gene/SNP & Cases & Controls & $P$-value ${ }^{\mathrm{a}}$ \\
\hline \multicolumn{4}{|l|}{ MSH2 (rs2059520) } & \multicolumn{3}{|c|}{$R A D 51135 \mathrm{G}>\mathrm{C}(\mathrm{rs} 1801320)$} & \\
\hline $\mathrm{A} / \mathrm{A}$ & 512 & 562 & 0.8 & $\mathrm{G} / \mathrm{G}$ & 915 & 952 & 0.5 \\
\hline $\mathrm{A} / \mathrm{G}$ & 471 & 489 & & $\mathrm{G} / \mathrm{C}$ & 193 & 216 & \\
\hline $\mathrm{G} / \mathrm{G}$ & 108 & 119 & & $\mathrm{C} / \mathrm{C}$ & 0 & 0 & \\
\hline MAF $^{\mathrm{b}}$ & 0.31 & 0.31 & & MAF $^{\mathrm{b}}$ & 0.09 & 0.09 & \\
\hline Hardy-Weinberg ${ }^{c}$ & & 0.41 & & Hardy-Weinberg ${ }^{c}$ & & 0.0005 & \\
\hline \multicolumn{4}{|c|}{ MLH1 Ile219Val (rs1799977) } & \multicolumn{3}{|c|}{$R A D 51172 \mathrm{G}>\mathrm{T}(\mathrm{rs} 1801321)$} & \\
\hline Ile/Ile & 543 & 568 & 0.78 & $\mathrm{G} / \mathrm{G}$ & 340 & 400 & 0.24 \\
\hline Ile/Val & 449 & 497 & & $\mathrm{G} / \mathrm{T}$ & 522 & 530 & \\
\hline Val/Val & 98 & 110 & & $\mathrm{~T} / \mathrm{T}$ & 236 & 236 & \\
\hline MAF $^{\mathrm{b}}$ & 0.3 & 0.31 & & MAF $^{\mathrm{b}}$ & 0.45 & 0.43 & \\
\hline Hardy-Weinberg $^{c}$ & & 0.93 & & Hardy-Weinberg ${ }^{c}$ & & 0.01 & \\
\hline \multicolumn{4}{|l|}{ MRE11A (rs601341) } & \multicolumn{3}{|c|}{ BRCA2 Asn991Asp (rs1799944) } & \\
\hline $\mathrm{G} / \mathrm{G}$ & 385 & 452 & 0.02 & Asn/Asn & 945 & 1058 & 0.03 \\
\hline $\mathrm{G} / \mathrm{A}$ & 530 & 566 & & Asn/Asp & 133 & 108 & \\
\hline $\mathrm{A} / \mathrm{A}$ & 190 & 156 & & Asp/Asp & 8 & 4 & \\
\hline MAF $^{\mathrm{b}}$ & 0.41 & 0.37 & & $\mathrm{MAF}^{\mathrm{b}}$ & 0.07 & 0.05 & \\
\hline Hardy-Weinberg ${ }^{c}$ & & 0.31 & & Hardy-Weinberg ${ }^{c}$ & & 0.49 & \\
\hline \multicolumn{4}{|c|}{ BARD1 Pro24Ser (rs1048108) } & \multicolumn{3}{|c|}{ OGG1 Ser326Cys (rs1052134) } & \\
\hline Pro/Pro & 515 & 514 & 0.18 & Ser/Ser & 615 & 647 & 0.93 \\
\hline Pro/Ser & 445 & 520 & & Ser/Cys & 422 & 455 & \\
\hline Ser/Ser & 138 & 138 & & Cys/Cys & 71 & 72 & \\
\hline MAF $^{\mathrm{b}}$ & 0.33 & 0.34 & & MAF $^{\mathrm{b}}$ & 0.25 & 0.26 & \\
\hline Hardy-Weinberg ${ }^{c}$ & & 0.71 & & Hardy-Weinberg ${ }^{c}$ & & 0.5 & \\
\hline \multicolumn{4}{|c|}{ FANCA Gly501Ser (rs2239359) } & \multicolumn{3}{|c|}{ TP53 Pro72Arg (rs1042522) } & \\
\hline Gly/Gly & 387 & 433 & 0.52 & Pro/Pro & 555 & 638 & 0.08 \\
\hline Gly/Ser & 524 & 543 & & Pro/Arg & 463 & 438 & \\
\hline Ser/Ser & 190 & 186 & & Arg/Arg & 85 & 97 & \\
\hline $\mathrm{MAF}^{\mathrm{b}}$ & 0.41 & 0.39 & & $\mathrm{MAF}^{\mathrm{b}}$ & 0.29 & 0.27 & \\
\hline Hardy-Weinberg ${ }^{c}$ & & 0.47 & & Hardy-Weinberg ${ }^{c}$ & & 0.08 & \\
\hline \multicolumn{4}{|c|}{ ERCC2 Lys751Gln (rs13181) } & \multicolumn{3}{|c|}{ RAD52 2259C > T (rs11226) } & \\
\hline Lys/Lys & 331 & 383 & 0.06 & $\mathrm{C} / \mathrm{C}$ & 561 & 568 & 0.4 \\
\hline Lys/Gln & 603 & 585 & & $\mathrm{C} / \mathrm{T}$ & 448 & 494 & \\
\hline Gln/Gln & 171 & 208 & & $\mathrm{~T} / \mathrm{T}$ & 92 & 108 & \\
\hline $\mathrm{MAF}^{\mathrm{b}}$ & 0.43 & 0.43 & & $\mathrm{MAF}^{\mathrm{b}}$ & 0.29 & 0.3 & \\
\hline Hardy-Weinberg ${ }^{c}$ & & 0.55 & & Hardy-Weinberg ${ }^{c}$ & & 0.97 & \\
\hline
\end{tabular}

${ }^{a}$ Genotype frequency $P$-value

${ }^{\mathrm{b}} \mathrm{MAF}=$ minor allele frequency

c $P$-value from Chi-square test

observed between TP53 rs1042522 (Pro72Arg) and risk of breast cancer. No significant associations with breast cancer were observed for the other nine SNPs studied.

\section{Discussion}

Breast cancer is a common, polygenic, and heterogeneous disease. Genetic epidemiology data suggest that part of breast cancer etiology can be explained by common, lowpenetrance alleles that increase susceptibility to breast cancer risk [13]. DNA repair is essential for maintaining genomic integrity. Deficiencies in the DNA repair pathway lead to genetic instability which in turn may lead to cancer development. Genetic polymorphisms in DNA repair genes may contribute to differential DNA repair capability between individuals [14]. In an attempt to identify lowpenentrance breast cancer susceptibility alleles, we 
Table 2 Genotype frequencies and risk estimates calculated using the recessive and dominant inheritance models

\begin{tabular}{|c|c|c|c|c|c|}
\hline Gene & SNP & Model & OR & $95 \% \mathrm{CI}$ & $P$-value \\
\hline \multirow[t]{3}{*}{$M S H 2$} & \multirow[t]{3}{*}{ rs 2059520} & Dominant & 1.05 & $0.89-1.23$ & 0.6 \\
\hline & & Recessive & 0.97 & $0.74-1.28$ & 0.83 \\
\hline & & & & & $0.76^{\mathrm{a}}$ \\
\hline \multirow[t]{3}{*}{$M L H 1$} & \multirow[t]{3}{*}{ rs1799977 } & Dominant & 0.94 & $0.8-1.11$ & 0.48 \\
\hline & & Recessive & 0.96 & $0.72-1.27$ & 0.76 \\
\hline & & & & & $0.5^{\mathrm{a}}$ \\
\hline \multirow[t]{3}{*}{$M R E 11 A$} & \multirow[t]{3}{*}{ rs601341 } & Dominant & 1.17 & $0.99-1.39$ & 0.07 \\
\hline & & Recessive & 1.36 & $1.08-1.71$ & 0.009 \\
\hline & & & & & $0.0087^{\mathrm{a}}$ \\
\hline \multirow[t]{3}{*}{$B A R D 1$} & \multirow[t]{3}{*}{ rs1048108 } & Dominant & 0.88 & $0.75-1.04$ & 0.15 \\
\hline & & Recessive & 1.08 & $0.84-1.39$ & 0.56 \\
\hline & & & & & $0.43^{\mathrm{a}}$ \\
\hline \multirow[t]{3}{*}{ FANCA } & \multirow[t]{3}{*}{ rs2239359 } & Dominant & 1.1 & $0.92-1.3$ & 0.3 \\
\hline & & Recessive & 1.09 & $0.88-1.37$ & 0.42 \\
\hline & & & & & $0.25^{\mathrm{a}}$ \\
\hline \multirow[t]{3}{*}{ ERCC2 } & \multirow[t]{3}{*}{ rs13181 } & Dominant & 1.13 & $0.95-1.35$ & 0.18 \\
\hline & & Recessive & 0.85 & $0.68-1.06$ & 0.16 \\
\hline & & & & & $0.89^{\mathrm{a}}$ \\
\hline \multirow[t]{3}{*}{$R A D 51$} & \multirow[t]{3}{*}{ rs1801320 } & Dominant & 0.93 & $0.75-1.15$ & 0.5 \\
\hline & & Recessive & & & \\
\hline & & & & & $0.5^{\mathrm{a}}$ \\
\hline \multirow[t]{3}{*}{$R A D 51$} & \multirow[t]{3}{*}{ rs1801321 } & Dominant & 1.16 & $0.98-1.39$ & 0.09 \\
\hline & & Recessive & 1.08 & $0.88-1.32$ & 0.46 \\
\hline & & & & & $0.13^{\mathrm{a}}$ \\
\hline \multirow[t]{3}{*}{ BRCA2 } & \multirow[t]{3}{*}{ rs1799944 } & Dominant & 1.41 & $1.08-1.83$ & 0.01 \\
\hline & & Recessive & 2.16 & $0.65-7.2$ & 0.2 \\
\hline & & & & & $0.0076^{\mathrm{a}}$ \\
\hline \multirow[t]{3}{*}{$O G G 1$} & \multirow[t]{3}{*}{ rs1052134 } & Dominant & 0.98 & $0.83-1.16$ & 0.85 \\
\hline & & Recessive & 1.05 & $0.75-1.47$ & 0.79 \\
\hline & & & & & $0.96^{\mathrm{a}}$ \\
\hline \multirow[t]{3}{*}{ TP53 } & \multirow[t]{3}{*}{ rs1042522 } & Dominant & 1.18 & $1-1.39$ & 0.05 \\
\hline & & Recessive & 0.93 & $0.68-1.25$ & 0.62 \\
\hline & & & & & $0.19^{\mathrm{a}}$ \\
\hline \multirow[t]{3}{*}{ RAD52 } & \multirow[t]{3}{*}{ rs11226 } & Dominant & 0.89 & $0.76-1.06$ & 0.19 \\
\hline & & Recessive & 0.9 & $0.68-1.21$ & 0.5 \\
\hline & & & & & $0.19^{\mathrm{a}}$ \\
\hline
\end{tabular}

${ }^{\text {a }} P_{\text {trend }}$

investigated the hypothesis that common variation in 11 DNA repair-related pathway genes modifies risk for breast cancer. We genotyped $12 \mathrm{SNPs}$ in a cohort of 2,286 Cypriot women (1,109 breast cancer patients and 1,177 healthy controls). We found that SNPs in BRCA2 and MRE11A may be associated with breast cancer risk.

For the BRCA2 991Asp allele, the additive model showed a significant trend $(P=0.0076)$ towards increased risk of breast cancer with the number of copies of the Asp allele among Cypriot women. It is located in the conserved BRC repeat region of the BRCA2 gene in exon 11 [15]. This variant has been found in many individuals with a family history of breast cancer and has been classified as a variant of no clinical significance in the Breast Cancer Information Core Database (BIC) [16]. On the other hand, in silico prediction methods suggest that this is a nontolerated amino acid substitution within the limits of confidence in the alignments [17]. Therefore, until functional data become available, the pathogenicity of this variant cannot be excluded, and it may be a variant that increases risk moderately, but is indeed, not highly penetrant. There was no association between the presence of the BRCA2 991Asp allele and family history of breast cancer. A moderately strong association of this BRCA2 polymorphism with malignant melanoma has been reported. The presence of this common $B R C A 2$ variant was associated with malignant melanoma risk $(P=0.002$ after Bonferroni correction), in over $9 \%$ of the cases studied. The authors suggested that this variant is not a neutral missense mutation and that follow-up studies should be undertaken in melanoma and breast cancer populations to precisely define its pathogenicity [18]. The role of this SNP in breast cancer risk has been investigated in the Multiethnic Cohort study and no association was found [19]. Previous studies that we performed in our population revealed a different spectrum of mutations in the BRCA1 and BRCA2 genes compared to other populations $[20,21]$. The over-representation of the BRCA2 Asn991Asp polymorphism in the breast cancer group supports that this variant is associated with an increased breast cancer risk among Cypriot women and it is possible that this association is characteristic only for the Cypriot population.

In the current study, there was also evidence for an increased breast cancer risk for women homozygous for the MRE11A rs601341 A allele. The MRE11A gene forms a complex with RAD50 and NBS1 genes which is involved in the cellular response to DNA double strand breaks. Defects in the members of this tri-complex are linked to increased chromosomal instability which leads to cancer [22]. To our knowledge, the role of rs601341 in breast cancer has not been investigated but a protective effect of this SNP against follicular lymphoma has been reported [23]. rs601341 may be in LD with another variant in the region. Functional studies will need to be performed in the future to identify the actual causal variant.

There are contradictory reports regarding the role of the TP53 Pro72Arg polymorphism and breast cancer. Our results suggest a marginal increased risk for breast cancer $(P=0.05)$ for carriers of the Pro allele. A meta-analysis conducted by the Breast Cancer Association Consortium concluded that this variant is not associated with breast cancer [24]. 
Our study has several strengths, including a high participation rate of eligible cases (98\%) and a sample from a homogeneous ethnic background (100\% of study participants are Greek Cypriots) thus reducing the bias due to population stratification. In addition, our study population (both cases and controls) was from all over the country minimizing potential selection bias. Limitations of this study are that our analysis did not consider the possibility of gene-gene interactions. It is possible that the risks observed are the result of interactions but we have not attempted to assess such effects since the estimate of an interaction effect will be unreliable because of small numbers. We also did not adjust for possible differences in lifestyle factors.

In conclusion our results suggest that genetic variation in the DNA repair pathway is associated with breast cancer risk in Cypriot women. The associations with SNPs rs1799944 and rs601341 should be considered for replication efforts in other larger studies to increase confidence in reported association and to clarify whether the association is only specific for the Cypriot population.

Acknowledgments We thank Rena Papachristoforou for her assistance in data collection. We also thank the patients and the healthy volunteers who participated in MASTOS without whom this research could not have been done. This work is supported by Cyprus Research Promotion Foundation (IPE) grants $0104 / 13$ and $0104 / 17$ and the Cyprus Institute of Neurology and Genetics.

\section{References}

1. Parkin DM, Bray F, Ferlay J et al (2005) Global cancer statistics, 2002. CA Cancer J Clin 55(2):74-108

2. Hamosh A, Scott AF, Amberger JS et al (2005) Online Mendelian Inheritance in Man (OMIM), a knowledgebase of human genes and genetic disorders. Nucleic Acids Res 33(Database issue): D514-D517. doi:10.1093/nar/gki033

3. Walsh T, King MC (2007) Ten genes for inherited breast cancer. Cancer Cell 11(2):103-105. doi:10.1016/j.ccr.2007.01.010

4. Bau DT, Mau YC, Ding SL et al (2007) DNA double-strand break repair capacity and risk of breast cancer. Carcinogenesis 28(8):1726-1730. doi:10.1093/carcin/bgm109

5. Kennedy DO, Agrawal M, Shen J et al (2005) DNA repair capacity of lymphoblastoid cell lines from sisters discordant for breast cancer. J Natl Cancer Inst 97(2):127-132

6. Oldenburg RA, Meijers-Heijboer H, Cornelisse CJ et al (2007) Genetic susceptibility for breast cancer: How many more genes to be found? Crit Rev Oncol Hematol 63(2):125-149. doi: 10.1016/j.critrevonc.2006.12.004

7. Goode EL, Ulrich CM, Potter JD (2002) Polymorphisms in DNA repair genes and associations with cancer risk. Cancer Epidemiol Biomarkers Prev 11(12):1513-1530

8. Kuschel B, Auranen A, McBride S et al (2002) Variants in DNA double-strand break repair genes and breast cancer susceptibility. Hum Mol Genet 11(12):1399-1407. doi:10.1093/hmg/11.12.1399
9. García-Closas M, Egan KM, Newcomb PA et al (2006) Polymorphisms in DNA double-strand break repair genes and risk of breast cancer: two population-based studies in USA and Poland, and meta-analyses. Hum Genet 119(4):376-388. doi:10.1007/ s00439-006-0135-z

10. Haiman CA, Hsu C, de Bakker PI et al (2008) Comprehensive association testing of common genetic variation in DNA repair pathway genes in relationship with breast cancer risk in multiple populations. Hum Mol Genet 17(6):825-834. doi:10.1093/hmg/ ddm354

11. Loizidou MA, Michael T, Neuhausen SL, Newbold RF, Marcou Y, Kakouri E et al (2008) Genetic polymorphisms in the DNA repair genes XRCC1, XRCC2 and XRCC3 and risk of breast cancer in Cyprus. Breast Cancer Res Treat. Epub ahead of print. doi:10.1007/s10549-007-9881-4

12. International HapMap Consortium (2005) A haplotype map of the human genome. Nature 437(7063):1299-1320. doi:10.1038/ nature 04226

13. Pharoah PDP, Antoniou A, Bobrow M et al (2002) Polygenic susceptibility to breast cancer and implications for prevention. Nat Genet 31:33-36. doi:10.1038/ng853

14. Mohrenweiser HW, Jones IM (1998) Variation in DNA repair is a factor in cancer susceptibility: a paradigm for the promises and perils of individual and population risk estimation? Mutat Res 400:15-24. doi:10.1016/S0027-5107(98)00059-1

15. Rapakko K, Heikkinen K, Karppinen SM et al (2006) Screening for RAD51 and BRCA2 BRC repeat mutations in breast and ovarian cancer families. Cancer Lett 236(1):142-147. doi: 10.1016/j.canlet.2005.05.032

16. Breast Cancer Information Core Database (BIC) http://research. nhgri.nih.gov/bic/

17. Fackenthal JD, Sveen L, Gao Q et al (2005) Complete allelic analysis of BRCA1 and BRCA2 variants in young Nigerian breast cancer patients. J Med Genet 42(3):276-281. doi:10.1136/ jmg.2004.020446

18. Debniak T, Scott RJ, Górski B et al (2008) Common variants of DNA repair genes and malignant melanoma. Eur $\mathrm{J}$ Cancer 44(1):110-114. doi:10.1016/j.ejca.2007.10.006

19. Freedman ML, Penney KL, Stram DO et al (2004) Common variation in BRCA2 and breast cancer risk: a haplotype-based analysis in the Multiethnic Cohort. Hum Mol Genet 13(20):24312441. doi: $10.1093 / \mathrm{hmg} / \mathrm{ddh} 270$

20. Hadjisavvas A, Charalambous E, Adamou A et al (2004) Hereditary breast and ovarian cancer in Cyprus: identification of a founder BRCA2 mutation. Cancer Genet Cytogenet 151(2): 152-156. doi:10.1016/j.cancergencyto.2003.09.020

21. Loizidou M, Marcou Y, Anastasiadou V et al (2007) Contribution of BRCA1 and BRCA2 germline mutations to the incidence of early-onset breast cancer in Cyprus. Clin Genet 71(2):165-170. doi:10.1111/j.1399-0004.2007.00747.x

22. van den Bosch M, Bree RT, Lowndes NF et al (2003) The MRN complex: coordinating and mediating the response to broken chromosomes. EMBO Rep 4(9):844-849. doi:10.1038/sj.embor. embor925

23. Rollinson S, Kesby H, Morgan GJ (2006) Haplotypic variation in MRE11, RAD50 and NBS1 and risk of non-Hodgkin's lymphoma. Leuk Lymphoma 47(12):2567-2583. doi:10.1080/10428 190600909743

24. Breast Cancer Association Consortium (2006) Commonly studied single-nucleotide polymorphisms and breast cancer: results from the Breast Cancer Association Consortium. J Natl Cancer Inst 98(19):1382-1396 